\title{
Coxiella burnetii
}

National Cancer Institute

\section{Source}

National Cancer Institute. Coxiella burnetii. NCI Thesaurus. Code C86328.

A species of aerobic, Gram negative, coccobacilli shaped bacteria in the phylum Proteobacteria. This species is obligately intracellular, sporeforming, acidophilic, pleomorphic and catalase positive. C. burnetti is pathogenic, being the causative agent of Q fever. 